INGURUAK [70] | 2021 | 47-69

http://dx.doi.org/10.18543/inguruak-70-2021-art03

ISSN 0214-7912

\title{
Integración: \\ el punto de vista de las personas inmigrantes latinoamericanas en Euskadi
}

\author{
Integration: \\ the point of view of Latin American immigrants in the Basque Country
}

\author{
Lucas Martín Gatica* \\ Universidad de Deusto
}

\begin{abstract}
RESUMEN: La inmigración en España tiene carácter estructural, con aras a aumentar en el transcurso de las décadas, donde personas de distintas culturas y orígenes comparten la vida cotidiana, las instituciones y los servicios. Esta realidad que ha venido tomando forma desde hace unas décadas plantea una serie de retos, entre ellos, la cuestión de la integración social. Analizamos las narrativas de personas inmigrantes latinoamericanas que residen en el País Vasco para explorar sus perspectivas con respecto a su propia integración y examinar la relación con las discusiones teóricas alrededor del concepto de integración. Nuestro estudio señala cómo las narrativas se acercan teóricamente a las definiciones más actuales de integración, las problematizan y dan posibles pistas acerca de una integración «ideal».
\end{abstract}

Palabras clave: Inmigración, Integración, Narrativas.

ABSTRACT: Immigration in Spain is structural in nature, with the aim of increasing over the decades, where people of different cultures and origins share daily life, institutions, and services. This reality that has been taking shape for a few decades poses a series of challenges, including the question of social integration. We analyze the narratives of Latin American immigrants residing in the Basque Country to explore their perspectives regarding their own integration and to examine the relationship with the theoretical discussions around the concept of integration. Our study points out how narratives theoretically approach the most current definitions of integration, problematize them and give possible clues about an «ideal» integration.

Keywords: Immigration, Integration, Narratives.

* Correspondencia a/Correspondence to: Lucas Martín Gatica. Universidad de Deusto - lucasmgatica@deusto.es - https://orcid.org/0000-0002-2176-6764 Cómo citar/How to cite: Martín Gatica, Lucas (2021). «Integración: el punto de vista de las personas inmigrantes latinoamericanas en Euskadi»; Inguruak, 70, 47-69. (http://dx.doi.org/10.18543/inguruak-70-2021-art03).

Recibido/Received: 9 diciembre, 2020; Versión final/Final version: 05 mayo, 2021.

ISSN 0214-7912 / (c) 2021 UPV/EHU

(c) (7) Esta obra está bajo una Licencia

Creative Commons Atribución-NoComercial-SinDerivadas 4.0 Internacional 


\section{INTRODUCCIÓN}

Desde finales del siglo xx el fenómeno inmigratorio en España ha cambiado la fisonomía y características de la sociedad (Moreno-Colom y De Alós, 2016). Esto trajo consigo una mayor diversidad en el plano social y cultural. De este modo, la inmigración se ha ido configurando como un fenómeno estructural, con aras a aumentar con el transcurso de los años (Aierdi Urraza, 2018; Cachón, 2009). Esta realidad que ha venido tomando forma desde hace décadas plantea una serie de retos, entre ellos, la cuestión de la integración social (Sales Ten, 2007). Es en este contexto que cobra relevancia el estudio y comprensión de los procesos relacionados a las narrativas de integración de las personas inmigrantes (Moreno Márquez, 2018).

Esta investigación ha tenido como objetivo explorar las perspectivas de las personas inmigrantes en Euskadi con respecto a qué entienden por integración y sus distintas esferas, a fin de comprender sus propios procesos de integración, y contrastar esas narrativas con las definiciones y distintos acercamientos teóricos a dicho concepto. Para este fin, partimos de una definición de integración como un proceso colectivo, que se contrapone al de asimilación y aculturación (Martín Rojo, 2003; Verdia Varela, 2020). Posteriormente, exploramos las narrativas de las personas inmigrantes en torno a ese concepto para examinar vínculos con las definiciones desplegadas. Por tanto, proporcionamos un análisis basado en entrevistas con personas inmigrantes y comparamos ese discurso con las definiciones de integración propuestas. Esto puede ser útil y colaborar para la elaboración de planes y políticas que contengan las necesidades y miradas de las personas inmigrantes y que, de igual manera, facilite la convivencia e interacción entre los autóctonos y los recién llegados.

Por tanto, el artículo se ha enfocado en las narrativas relacionadas a las distintas aristas del concepto de integración que la población inmigrante latinoamericana posee, y lo que esto pueda señalar con relación al debate de la ciudadanía asociado al fenómeno migratorio, ya que el proceso de construcción de ciudadanía precisa, también, la perspectiva de las personas inmigrantes, los ciudadanos recién incorporados (Verdía Varela et al., 2020).

\subsection{Diseño metodológico}

Nuestra estrategia metodológica es de carácter cualitativa. De este modo, toda la evidencia empírica sobre narrativas y discursos de las personas inmigrantes proviene del análisis de las entrevistas realizadas en el marco de una investigación más amplia. Se han realizado 10 entrevistas con personas nacidas en América Latina, con edades comprendidas entre los 18 y 65 años que residen en la Comunidad Autónoma del País Vasco con al menos cinco años de antigüedad ${ }^{1}$. Hemos considerado que ese era el tiempo mínimo indispensable

${ }^{1}$ La media de años de residencia de las personas participantes es de 6,5 años. 
para que las personas informantes hayan recorrido un tiempo de acomodación en Euskadi como la superación de las primeras dificultades que pueden hallarse al llegar a un nuevo país. También, en líneas generales, pasados los cinco años de estancia en el nuevo país es posible hallar mayor estabilidad en las situaciones administrativo-legal, laboral y familiar (Iglesias, Rua y Ares, 2020).

La muestra fue confeccionada a través del contacto directo con asociaciones de inmigrantes del ámbito del País Vasco y haciendo uso del método de bola de nieve. Primero hemos contactado con dos organizaciones que trabajan en el ámbito de la inmigración y estas primeras fuentes nos han contactado con los iniciales participantes que, a su vez, nos han contactado con otras personas inmigrantes participantes en el estudio. Mediante esta fórmula hemos podido acceder a perfiles previstos en la muestra y que recogen la diversidad de personas inmigrantes y cierto grado de saturación en la información de interés para el trabajo. Las entrevistas fueron realizadas en el año 2020 y se analizaron en el software Atlas.ti. Las narrativas de las personas participantes irán apareciendo en el texto bajo un seudónimo.

La elección de Euskadi como terreno para el estudio tiene que ver con que esta comunidad autónoma se ha caracterizado por recibir flujos inmigratorios de forma más lenta y en menor porcentaje si se la compara con otras Comunidades Autónomas (C.A.) del Estado, lo que podría traducirse en que el fenómeno inmigratorio sigue siendo, de alguna manera, novedoso, y las políticas destinadas a él son también relativamente nuevas. A su vez, es una C.A. que ha mostrado importantes aumentos de sus tasas inmigratorias, sobre todo en su dimensión latinoamericana, en los últimos años (INE, 2020; Ikuspegi, 2020).

Tabla 1. Características demográficas de las personas participantes

\begin{tabular}{|c|c|c|}
\hline \multirow{4}{*}{ Sexo } & Categorías & $\begin{array}{c}\text { Número de } \\
\text { participantes }\end{array}$ \\
\hline \multirow{4}{*}{ Edad } & Hombres & 4 \\
\cline { 2 - 3 } & Mujeres & 6 \\
\cline { 2 - 3 } & $18-29$ & 4 \\
\cline { 2 - 3 } & $30-44$ & 4 \\
\hline \multirow{4}{*}{ País de origen } & $45-65$ & 2 \\
\cline { 2 - 3 } & Colombia & 3 \\
\cline { 2 - 3 } & Nicaragua & 3 \\
\cline { 2 - 3 } & Venezuela & 2 \\
\cline { 2 - 3 } & Perú & 1 \\
\cline { 2 - 3 } & Argentina & 1 \\
\hline
\end{tabular}

Fuente: Elaboración propia. 
Lo que se pretende con el enfoque elegido para realizar esta investigación es contribuir al análisis de las experiencias migratorias de las personas latinoamericanas desde sus propias voces y que estas puedan orientar futuras investigaciones, así como evaluar potenciales aplicaciones en torno a sus procesos integrativos (Martínez de Lizarrondo, 2009). Aquí nos interesa ya no la integración en sí —como objetivo más o menos medible- sino las significaciones que surgen en torno a ella en el despliegue de las narrativas, ya que la sociedad de acogida, en este caso, la vasca, está en un proceso de compartir y construir un futuro con los nuevos integrantes de dicha sociedad, las personas inmigrantes (Pacto Social Vasco para la Migración, 2018). Por ello, se hace necesario aproximarse y darle lugar a las narraciones, opiniones y valoraciones de este grupo particular, tal y como se viene indicando en la literatura previa (Maalouf, 2009; Verdía Varela et al., 2020).

\subsection{Breve contextualización de la inmigración latinoamericana en Euskadi}

En el año 2020 el porcentaje de población de origen inmigrante en Euskadi era de 10,9\%, lo que se traducía en 241.193 personas empadronadas nacidas fuera del Estado español (INE, 2020). Ese 10,9\% es el dato más alto de la historia de Euskadi, sin embargo, se encuentra por debajo del porcentaje a nivel nacional: 15,2\% (INE, 2020). Asimismo, a nivel estatal el colectivo latinoamericano ha superado en número a las personas inmigrantes provenientes de África. En el periodo que va del año 2000 al 2005 el aumento inmigratorio del grupo latinoamericano fue de un 250\% (Vicente Torrado, 2006). Fue en ese mismo año, 2005, cuando las personas procedentes de América Latina superaron en número a los inmigrantes procedentes del norte de África y del este europeo en España (Göttsch, 2010), consolidándose como un grupo de importante relevancia socioeconómica, demográfica y política. Así, las estadísticas de las personas latinoamericanas en España ponen en evidencia la importancia capital de este colectivo para el conjunto de la sociedad española, sus alcances, logros y miras a futuro. $\mathrm{Y}$ al igual de lo que sucede en Europa, los colectivos de personas inmigrantes son fundamentales para el desarrollo económico, laboral y demográfico de las sociedades y, en el caso de España, es el colectivo latinoamericano esencial en esas materias (Lasheras Ruiz, 2018).

Ahora bien, enfocando las cifras en Euskadi vale señalar especialmente el peso de las personas inmigrantes extracomunitarias - 80,5\% de inmigración extracomunitaria en Euskadi frente al 67,7\% de España (INE)—. Es decir, en comparación con la media española en Euskadi se observa un peso más fuerte de latinoamericanos/as y africanos/as que en otras partes del estado. Asimismo, Euskadi pasó de tener, en el año 2000, tan solo 11.545 personas inmigrantes latinoamericanas empadronadas a tener 98.588 personas latinoamericanas residentes en 2018 (INE). Por tanto, es un grupo particularmente vital y significativo (Ikuspegi, 2018). 
Tabla 2. Evolutivo de las principales nacionalidades de personas inmigrantes latinoamericanas en Euskadi 2000-2018 (INE)

\begin{tabular}{|l|r|r|r|r|}
\hline \multirow{2}{*}{} & \multicolumn{4}{|c|}{ Euskadi } \\
\cline { 2 - 5 } & \multicolumn{2}{|c|}{2000} & \multicolumn{2}{c|}{2018} \\
\hline Total de latinoamericanos/as & 11.545 & $100,0 \%$ & 98.588 & $100,0 \%$ \\
\hline Colombia & 1.481 & $12,8 \%$ & 19.558 & $19,8 \%$ \\
\hline Bolivia & 83 & $0,7 \%$ & 11.453 & $11,6 \%$ \\
\hline Nicaragua & 71 & $0,6 \%$ & 8.589 & $8,7 \%$ \\
\hline Ecuador & 343 & $3,0 \%$ & 8.497 & $8,6 \%$ \\
\hline Brasil & 1.242 & $10,8 \%$ & 6.539 & $6,6 \%$ \\
\hline Paraguay & 47 & $0,4 \%$ & 6.516 & $6,6 \%$ \\
\hline Venezuela & 1.549 & $13,4 \%$ & 6.232 & $6,3 \%$ \\
\hline Argentina & 1.729 & $15,0 \%$ & 5.678 & $5,8 \%$ \\
\hline Perú & 512 & $4,4 \%$ & 5.326 & $5,4 \%$ \\
\hline Honduras & 41 & $0,4 \%$ & 5.294 & $5,4 \%$ \\
\hline
\end{tabular}

Fuente: Elaboración propia a partir de datos de INE.

Teniendo en cuenta la composición de la inmigración latinoamericana en Euskadi, a saber, un colectivo sensiblemente feminizado, sobre todo en ciertos países de procedencia, con mayor concentración en los grandes centros urbanos, marcadamente de carácter asalariada, con tasas de nacionalización altas en comparación con otros orígenes (Shershneva, Fernández, Oleaga, 2018), creemos que nuestra muestra de 10 casos se aproxima relativamente a las características globales del colectivo latinoamericano ya que de nuestras personas participantes $60 \%$ son mujeres, $80 \%$ viven en alguna de las tres capitales vascas con mayor concentración en Bilbao-, el 70\% son trabajadores/as asalariados/as, su edad media es de 36 años y los cinco países de procedencia aquí representados conforman las principales procedencias de este colectivo en Euskadi. Es decir, a grandes rasgos las personas participantes conforman parte de los principales países de orígenes de las personas inmigrantes en Euskadi y se ha intentado contemplar la leve mayoría de las mujeres, la edad media y el tiempo de residencia promedio del colectivo.

Puesto esto, hemos utilizado una única herramienta de recogida de información: la entrevista en profundidad. Esta herramienta procura comprender la perspectiva del informante, que es explicada y puesta en sus propias palabras (Taylor y Bogdan, 1987) y de este modo nos permite aproximarnos a las problematizaciones del concepto de integración. Creemos que esta técnica nos permite observar el fenómeno de la integración desde la óptica privilegiada de las personas inmigrantes. Al mismo tiempo, la técnica de la entrevista en profundidad nos permite acercarnos a diferentes vivencias y experiencias vitales de las personas inmigrantes latinoamericanas con el fin de analizarlas y compararlas y poder comprender tanto adversidades como los principales factores vinculados a la integración. 
Las entrevistas fueron de naturaleza semiestructuradas, pautadas previamente en un guion de preguntas que contienen las dimensiones y factores que nos interesaban analizar y explorar (etapa previa a emigrar, integración, relaciones sociales, empleo, cambio y decisiones, paternidad/maternidad, género, euskera, ámbito público). Las entrevistas fueron flexibles y de una hora de duración aproximadamente, cubriendo muchos temas, aunque aquí hemos centrado nuestro análisis en las reflexiones que los/as participantes hacen sobre el concepto de «integración». Así, se consideró que esta técnica nos permitía dar voz al colectivo de personas inmigrantes latinoamericanas en Euskadi y examinar, a partir de sus narraciones, los factores vinculados a la integración de dicho colectivo. En síntesis, adoptamos un enfoque centrado en las personas inmigrantes para tensar y sondear el concepto de integración y sus dimensiones.

Al recopilar narrativas e historias de la vida real se pueden obtener conocimientos valiosos que ayuden a comprender en mayor profundidad la perspectiva de las personas inmigrantes y las experiencias vividas por ellas. Este acercamiento también puede ayudar a desarrollar una comprensión de cómo se pueden cambiar y mejorar, por ejemplo, las políticas de integración (Brännström et al., 2018). Según Smith (2005) las perspectivas y narrativas «excluidas» proporcionan un punto de partida para investigar cómo los procesos institucionales y sociales dan forma a los mundos cotidianos en los que las personas viven y actúan. Al adoptar un enfoque similar, utilizamos las narraciones y discursos de las propias personas inmigrantes para explorar y analizar sus conceptualizaciones y experiencias de integración.

El texto está estructurado en tres partes. Primero, aportamos una breve problematización sobre el concepto de integración. Luego, realizamos un análisis y presentación de las narrativas de las personas inmigrantes en torno a ese concepto y sus posibles avatares. Finalmente, se exponen los principales aportes.

\section{DE LA ASIMILACIÓN A LA INTEGRACIÓN SOCIAL}

La integración es un constructo complejo y multidimensional, que posee una naturaleza polifacética y de difícil reducción (Godenau et al., 2015). El concepto ha venido cobrando relevancia e importancia en los estudios y los medios de comunicación y ocupa discursos de gobiernos y organizaciones internacionales (Gil, 2011). Así, el término integración ha sido imbuido de diferentes significados a lo largo de las décadas. En España, por ejemplo, se ha utilizado para describir una situación más cercana a la asimilación, principalmente por aquellos que atribuyen la responsabilidad principal a las personas inmigrantes de adaptarse a los hábitos y costumbres de la sociedad receptora pero también ha sido usado para referirse a la igualación de derechos y responsabilidades de todos los miembros de la sociedad (Verdía Varela et al., 2020). Para Cachón (2008) la integración, en el escenario español, puede utilizarse en un sentido u otro según la ideología del interlocutor, lo 
que complejiza la cuestión y otorga ambigüedad al término. Este concepto es todo un desafío para las ciencias sociales, sobre todo cuando se lo analiza en contextos migratorios. De este modo, no habría una sola forma de acercarse o medir la integración ni una forma única de entenderla (Gil, 2011; Declaración de Zaragoza, 2010).

Ahora bien, el estudio de los procesos de integración de las personas inmigrantes ha estado presente desde hace años en la academia. Ya en la segunda década del siglo pasado la Escuela de Chicago se interesó por las interacciones entre los diferentes grupos de la sociedad norteamericana, principalmente por cuestiones relativas a la exclusión por motivos étnicos o raciales (Park y Burgess, 1921; Hughes y Hughes, 1952). Posteriormente la teoría de la asimilación, hoy en desuso, se mostraba como la opción más competitiva para el estudio de la integración social. El modelo teórico de la asimilación conceptualiza a la integración como un proceso unidireccional y en el cual todo el peso de la responsabilidad recae en las personas inmigrantes. El modelo procura la homogeneidad, evitando la diversidad cultural, intentando mantener estabilizadas a las sociedades que acogen inmigrantes. Este modelo plantea una posición monocultural donde el proceso de integración tiene un único desarrollo (Lamphere, 2007), en el cual las personas inmigrantes deben adaptarse y acomodarse a la sociedad a la que llegan. Por tanto, entendiendo la asimilación como algo deseable y natural del contacto intercultural, el resultado esperable es la eliminación de la discriminación, la desigualdad estructural y el prejuicio (González-Rábago, 2014). Este modelo fue ampliamente criticado y luego aparecerían marcos de estudio más complejos como el modelo de aculturación de Berry (1990), el Modelo Interactivo de Aculturación desarrollado por Bourhis et al. (1997), el Modelo Ampliado de Aculturación Relativa (Navas et al., 2004) y las lecturas del melting pot, el pluralismo cultural, el multiculturalismo y el interculturalismo (Ares y Fernández, 2017).

También la psicología transcultural se ha dedicado al estudio del proceso migratorio. En esa línea, la psicología transcultural estudia los fenómenos psicosociológicos que surgen como consecuencia del abandono de la sociedad de origen y su posterior instalación en una nueva sociedad, donde se produce el contacto con los autóctonos, hecho que involucra cambios en la identidad, los valores y los comportamientos tanto de las personas como de los grupos de ambas tradiciones culturales (Retortillo, 2009). En ese sentido, migrar produce transformaciones psicosociales en los propios migrantes y, también, en las denominadas sociedades receptoras o de acogida. Por ello, la migración ha sido definida como un «hecho social total» (Sanz, 2009) que tiene repercusiones sobre la totalidad de la sociedad de destino, pero también, en la sociedad de origen.

De igual modo, actualmente la temática de la integración continua vigente y forma parte central de importantes investigaciones en ciencias sociales, como también sigue siendo un término complejo y controvertido (Erdal y Oeppen, 2013). La literatura relacionada a esta temática brinda una variedad de términos vinculados a la integración social (García Cívico, 2010). En esa línea, se han propuesto términos como acomodación (Zapata-Barrero, 2002), social cohesion (Zetter y Flynn, 2005) o inserción laboral. Este último, más centrado 
en la vinculación entre programas sociales y políticas públicas (González-Rábago, 2014). De ahí que estos términos para hablar de las relaciones entre población autóctona y extranjera suelen ser tomados como sinónimos (Hamberger, 2009).

El término asimilación, fruto del trabajo de la Escuela de Chicago (Park y Burgess, 1921), involucra a un proceso de carácter más unilineal en el cual los inmigrantes deben adaptarse a la nueva sociedad, y ha sido utilizado como sinónimo del término aculturación. De alguna manera, la conceptualización de integración que adoptamos en este artículo está en contraposición a conceptos de connotación negativa, como es el caso de la asimilación «que pretende que los inmigrantes se incorporen a la sociedad receptora no sólo desde un punto de vista civil o político, sino incluso que asuman los rasgos culturales prevalecientes» (Sebastiani, 2009: 49). En definitiva, el proceso de integración de las personas inmigrantes debe tener en cuenta el establecimiento de relaciones interpersonales basadas en ciertos valores comunes que incluyen el respeto mutuo, el derecho a la diferencia y el diálogo. Por ende, la finalidad de la integración debe estar basada en cierto grado de cohesión social que respete e iguale los derechos de todas las personas, a diferencia de una simple coexistencia de distintos grupos culturales en un solo territorio (Meer y Moddod, 2012).

¿Qué se entiende por integración social? ¿Qué constituye una integración exitosa? ¿Quién está implicado? ¿Qué factores tienen más peso en el proceso de integración? ¿Qué papel cumple cada actor implicado? ¿De quién es la responsabilidad de la integración? ¿Sólo del inmigrante o los autóctonos deben formar parte activa del proceso? Sobre estos interrogantes hay disensos y discusiones (Iglesias de Ussel, 2010). Sin embargo, en cuanto a los documentos oficiales y políticas relacionadas a la integración de la población inmigrante suele haber amplio consenso acerca de que es una responsabilidad mutua, colectiva, multidimensional, que debe involucrar a los distintos estamentos gubernamentales, entre otras características (Megías Quirós, 2007).

Así, actualmente, las instituciones y gobiernos adoptan ideas que rechazan plenamente aquella idea de asimilación. Por ejemplo, la Unión Europea define la integración como «un proceso bidireccional y dinámico de ajuste mutuo por parte de todos los inmigrantes y residentes de los Estados miembros que implica el respeto de los valores básicos de la Unión Europea» (Consejo de Ministros de Justicia y Asuntos de Interior de la Unión Europea, 2014: 2). En el ámbito español, el Plan Estratégico de Ciudadanía e Integración da una definición similar: «la integración social, es entendida como un proceso bidireccional, de adaptación mutua y de acomodación, y que afecta al conjunto de la ciudadanía, tanto a los españoles como a los de origen extranjero, es un proceso multidimensional y complejo que plantea desafíos políticos y prácticos que es preciso afrontar» (2014: 72). En esa línea, el «término integración social ha sido discutido en las últimas décadas por su tinte asimilacionista y en todo caso se ha aceptado su comprensión en términos de bidireccionalidad, como ajuste de poblaciones diversas en cultura y orígenes en una nueva pauta intercultural que las recoge, asume y sintetiza» (V Plan de actuación en el ámbito de la ciudadanía, interculturalidad e inmigración, Gobierno Vasco, 2020: 11). 
Con todo, el concepto de integración va más allá de un modelo normativo y es el más utilizado en la actualidad para referirse al proceso de contacto e integración de personas inmigrantes en una nueva sociedad. En definitiva, debido a su capacidad de dar sentido y significado al proceso de inserción y adaptación de los colectivos inmigrantes en las sociedades de destino, el término integración continúa vigente y es utilizado en la gran mayoría de la literatura como eje central de estudio en esta área (González-Rábago, 2014).

De forma general, es posible pensar la integración de las personas inmigrantes teniendo en cuenta tres variables: a) los vínculos de las personas inmigrantes con las instituciones públicas y con la sociedad del país de acogida; b) los procesos de inserción social e interacción de las personas inmigrantes y la sociedad de destino y; c) el resultado de estos procesos, que se traduciría en el reconocimiento de derechos y obligaciones o no, y qué tipo de gestión de la diferencia cultural se decanta de esos procesos (De Lucas, 2008). Esta definición es una aproximación formal y poco nos dice sobre qué piensan y experimentan las personas inmigrantes sobre esos procesos. Puesto esto, el resultado del trabajo de campo con las personas entrevistadas da cuenta de la complejidad y la multiplicidad de variables y factores para tomar en consideración en el proceso de incorporación de las personas inmigrantes en las sociedades de acogida.

Ahora bien, siguiendo a Solé (1981) el concepto de integración sociocultural es un proceso en el cual las personas inmigrantes se adentran en la estructura ocupacional y aceptan de forma progresiva a las instituciones, creencias, valores y símbolos de la sociedad de destino. Según la autora, la integración estaría dividida operativamente en tres niveles: el estructural, relacionado con el acceso al empleo; el cultural, vinculado con el ejercicio del derecho a la diferencia y aceptación de unos parámetros de convivencia; y el jurídico, como garantía de igualdad ante la justicia (Solé et al., 2002).

Entre otros intentos por definir la integración podemos mencionar a Blanco quien señala que en:

las sociedades occidentales de modos de producción capitalista, entenderemos por integración la incorporación de los inmigrantes a una sociedad que tenga como resultado una estratificación social no basada en el origen, raza, etnia o religión de las poblaciones integrantes, culminando el proceso con un sentimiento de pertenencia a la comunidad de que se trate. Es decir, se hablará de integración cuando los grupos inmigrantes se incorporen a la estructura de la sociedad de acogida de forma igualitaria a la población autóctona, y ambos desarrollen sentimientos de solidaridad suficientes como para reconocerse y ser reconocidos como miembros de la sociedad en la que conviven. (Blanco, 1993: 230)

Por su parte, Pennix y Martiniello (2006) propusieron una definición breve y básica que contiene al proceso, la subjetividad y la estructura social: el proceso a través del cual uno se convierte en una parte aceptada de la sociedad. Así, de forma general, la integración po- 
dría entenderse como el proceso de aproximación entre dos culturas diferentes que se encuentran en situación de compartir un mismo espacio.

Otras definiciones sobre el concepto de integración apuntan a las relaciones sociales y la conceptualizan teniendo en cuenta el grado de cohesión o desorganización de las interacciones, los valores y prácticas culturales (Pujadas, 1993), centrándose en la relación dialéctica entre grupos e individuos, acentuando bien las diferencias particulares como un elemento distorsionador (Ehrkamp, 2006) o subrayando las diferencias entendiéndolas como elementos de enriquecimiento (Eriksen, 2011; Tharmalingam, 2011).

La aproximación que realiza Giménez a continuación resume someramente las antes presentadas:

Proceso de adaptación mutuo de dos segmentos socioculturales, mediante el cual, a) la minoría se incorpora a la sociedad receptora en igualdad de condiciones, derechos, obligaciones y oportunidades con los ciudadanos autóctonos, sin que ello suponga la pérdida de sus culturas de origen; y b) la mayoría acepta e incorpora los cambios normativos, institucionales e ideológicos necesarios para que lo anterior sea posible. En ella se contempla la multidimensionalidad del fenómeno en sus aspectos socioeconómicos y culturales, propugna la igualdad de derechos y responsabiliza también a la sociedad receptora. (1996 en Pumares, 1998: 296)

Más allá de las discusiones en torno a la integración y las diversas posiciones teóricas, la asunción de una o varias definiciones dependerán de los intereses y naturaleza de la investigación. En ese sentido, rastrearemos y exploraremos narrativas que circunden estas definiciones y que nos pueden hablar de integración en alguna de sus dimensiones. Es decir, teniendo en cuenta estas definiciones se intentará examinar en las narrativas de las personas inmigrantes latinoamericanas que residen en Euskadi el concepto de integración, sus críticas y posibles factores comunes.

\section{RESULTADOS}

A continuación se muestran los principales hallazgos comunes en torno al concepto de integración según las narrativas de las personas latinoamericanas que residen en Euskadi. Son de destacar tanto la equivocidad del término, la relevancia del factor cultural y laboral como sus críticas.

\subsection{La integración como un concepto difuso, próximo a las definiciones gubernamentales y factible de ser criticado}

Como se ha apuntado arriba, la integración no es un término inequívoco ni claro. De manera general, hace referencia al proceso según el cual una persona o grupo de ellas se in- 
serta de forma temporal o estable en un nuevo entorno social. Esta nueva incorporación tendría que darse con ciertas condiciones como la igualdad de derechos y acceso a lo público (Iglesias de Ussel, 2010). De igual modo, parte de los participantes han señalado lo vago y poco claro que es un término como el de «integración»:

«Es bastante relativo qué es “integración”. Puede ser toda la cuestión del acceso y derechos a la vivienda, trabajo, relaciones sociales, por ejemplo. Pero también puede usarse para suplantar la cultura y tradiciones de una persona. Hay que tener cuidado.» (Andrés)

«No termino de entender completamente eso de la “integración”. No sé lo que significa específicamente porque para alguien podría tener un sentido y para mí puede tener otro sentido esa palabra.» (Erick)

«No sé, tengo mis dudas sobre qué podría ser “integración”. Creo que no es ni que la persona pierda todo su trasfondo cultural pero tampoco es que se mimetice o confunda con su nueva sociedad o país.» (Vanesa)

Aquí partimos desde un marco teórico que comprende a la integración como el establecimiento de relaciones interculturales positivas, junto con una dinámica social que fomente la interacción, el diálogo y el intercambio entre los diferentes grupos y ciudadanos (Verdía Varela et al., 2020). Esto está en contraste con la mera coexistencia de los grupos culturales en un territorio. De alguna manera, el objetivo de una integración plena es alcanzar una cohesión social que garantice los derechos individuales de todas las personas (Torres, 2011; Meer y Moddod, 2012). Para ello, es imprescindible una participación social e interacción activa en el conjunto social. Al mismo tiempo, es fundamental lograr un diálogo intercultural que posibilite negociar las condiciones y normas que rigen las relaciones sociales (Evanoff, 2006). Estos elementos aparecen en las narrativas de los participantes:

«Sin intercambios sociales, sin contacto con la gente de aquí, sin reconocimiento mutuo no es posible hablar de integración o inserción.» (Cora)

«Debe existir la posibilidad de discutir y llegar a acuerdos sobre ciertas cosas con la gente autóctona. Integración no es solo vivir en la misma ciudad, en el mismo pueblo. Debe haber reconocimiento y escucha desde ambos lados.» (Fernanda)

En esa línea, observamos narrativas acerca de la integración rotundamente contrarias a lo que podríamos pensar que es el asimilacionismo. Se observa una tendencia en todos los entrevistados en diferenciar u oponer de forma manifiesta la asimilación a la integración, como lo ilustra la anterior cita de Vanesa o los siguientes ejemplos:

«Una cosa es integrarte y otra bien diferente es perder tu origen y tu cultura.» (Nicolás)

"Lo que te comentaba antes, hay que insertarse e integrarse en los códigos y costumbres del nuevo país, pero sin negar ni perder tus propias costumbres y códigos.» (Leined) 


\subsection{Diversidad cultural: reconocimiento y diálogo}

Así pues, de manera manifiesta los entrevistados diferencian y contraponen lo que ellos entienden por integración social al concepto de asimilación o aculturación, pero añaden que ellos también deben "reconocer», "dialogar» y aceptar normas de la nueva sociedad. Asimismo, es de destacar el lugar que ocupa lo cultural en estas definiciones dadas por las personas entrevistadas:

«Una persona que viene del exterior y entra en una nueva sociedad, tiene que adaptarse al estilo de vida, tiene que adaptarse a la cultura, a las costumbres de la sociedad dónde vive. Pero no tiene porqué despojarse de sus raíces, de su cultura, de su idioma.» (Miriam)

«Integrarse es vivir las costumbres de este lugar, pero siempre recordando quién eres, de dónde vienes y cuáles son tus costumbres [. . .] Creo que este es el camino para integrarse, quiero decir, integrarse con la posibilidad de mantener tu cultura.» (Mateo)

«Tiene que estar presente la posibilidad de que si quiero realizar una actividad relacionada con mi cultura, sea posible. Si quiero transmitir mis tradiciones, poder hacerlo y tenerlo facilitado.» (Fernanda)

Con relación a estas cuestiones, hemos observado discursos que apuntan a una «integración cultural mixta» ya que al tiempo que ponderan mantener sus costumbres y patrones culturales, admiten que han ido progresivamente adquiriendo las costumbres españolas y/o vascas.

\subsection{La participación laboral y cívica}

Por otro lado, como lo plantea la definición de Solé arriba apuntada, el hecho de tener empleo y lo que ello implica - acceso a ciertos derechos sociales, por ejemplo— conlleva un estatus civil que contribuye a ser «reconocido», lo que facilita la convivencia con la población autóctona. Es decir, la esfera del empleo y la participación laboral de los/as inmigrantes es un nivel primordial y básico del proceso de integración y del sentirse inserto en la nueva sociedad.

«Lo primero para que alguien se integre es poder trabajar, tener un trabajo [...] Creo que si no hay trabajo, entonces, la integración no es posible; puede haber una idea o algo parecido a integración, pero no es integración.» (Ángela)

«Sin trabajo la integración es imposible. Sin trabajo no hay ingresos económicos ni las mínimas interacciones sociales para poder comenzar a hablar de integración.» (Erick)

«Además de lo obvio como es tener trabajo y relaciones sociales, me parece que es muy importante la cuestión de poder disfrutar de los mismos derechos y beneficios 
que tienen los que nacieron aquí: salud, educación, vivienda, participación política; me parece.» (Mateo)

Igualmente que la mención al empleo, varios participantes señalan la importancia de acceder a los derechos y servicios de igual manera que los autóctonos - como lo hace Mateo arriba-y la necesidad de participar cívicamente e interesarse por los asuntos políticos:

«Entiendo que integrarte es también poder participar en los debates de la sociedad, votar, interesarte por la política, sentirte parte de esa sociedad y que puedes influir de alguna manera en algún cambio.» (Nicolás)

Según plantean distintos informes, la participación y acceso a la esfera política y participativa de las personas inmigrantes son, todavía, limitados, lo que afecta su reconocimiento como ciudadanos plenos y restringe sus legítimos intereses y derechos (Iglesias et al., 2020) y las personas inmigrantes aquí entrevistadas también lo señalan.

\subsection{El tiempo de residencia}

No obstante, además del empleo, otras investigaciones relacionan los niveles de integración y las perspectivas de movilidad social con el tiempo de residencia en el país (Fernández y Ortega, 2008; Diaz-Serrano, 2013; Ikuspegi, 2020), algo que nuestros participantes también indican:

«Seguramente que los años que uno lleve viviendo aquí tienen que ver con todo esto. No es lo mismo una persona que lleva solo dos años viviendo y trabajando, que otra que ya tiene una década e hijos que han nacido aquí.» (Vanesa)

«En mi caso es distinto porque al ya vivir aquí hace más de 13 años, hay cosas que entiendo y he hecho carne. Tal vez a un recién llegado le cueste más.» (Andrés)

Como se ha señalado a medida que aumenta el tiempo de residencia, las personas inmigrantes tienden a recapitalizarse con el desarrollo del aprendizaje del idioma, el reconocimiento de titulaciones, la adquisición de competencias y hábitos laborales nuevos, etc. (Iglesias et al., 2020). Nuestras narrativas indican, de cierta manera, que las personas inmigrantes son conscientes de que a mayor tiempo de residencia mayor emparejamiento socioeconómico con la población autóctona.

Por otra parte, las redes sociales suelen jugar un papel decisivo en las decisiones de emigrar a uno u otro destino. En la mayoría de las personas participantes se observa que la elección de vivir en el País Vasco está vinculada a la previa existencia de una red de apoyo en el lugar y que ésta tiene impacto en los primeros momentos de llegada y ayuda a comenzar a insertarse. Así, esa red social inicial ha sido primordial para dar los primeros pasos en el nuevo país: 
«La verdad que antes de venir a Euskadi no tenía mucha información del sitio. Como te comenté vine aquí porque estaba mi tía y mi prima. Ellas me acogieron y me dieron una mano en el primer momento. Si no hubieran estado ellas, tal vez hubiera ido para Madrid o Barcelona.» (Miriam)

«Hoy puedo decir que estoy bastante inserto en el País Vasco, he conocido a mi pareja aquí, tengo amigos, pero si no hubiera sido porque antes de venir estaba mi hermano, no hubiera venido. No estaba en mi radar venir a vivir a Tolosa.» (Andrés)

Todo ello nos muestra la importancia y lo fundamental de las redes familiares y sociales previas a la emigración ya que proporcionan protección social, económica y afectiva.

\subsection{Integración como un camino de ida y vuelta}

Al igual que recoge el último Plan de Integración de la Unión Europea (2020), la integración es un proceso de doble sentido para las personas inmigrantes. Por tanto, en la mayoría de las narrativas aparece la idea de que la integración no depende solo de ellos, los inmigrantes, sino que atañe también a los autóctonos y las instituciones del país de acogida:

«Hay que trabajar en dos sentidos, la integración no recae solamente en nosotros. El inmigrante, tiene que hacer y aportar. Pero los autóctonos también deben acompañar y ayudar.» (Cora)

«Debemos respetar las normas del lugar al que llegamos; la sociedad de aquí también debe colaborar para que nos integremos, claro. Es fundamental que los gobiernos y políticos fomenten eso.» (Mateo)

\subsection{Convivencia}

Otra dimensión relacionada con la integración de las personas inmigrantes que aparece en nuestras narrativas tiene que ver con la convivencia. Según se recoge en las encuestas y barómetros los episodios de xenofobia son esporádicos y los niveles de convivencia entre población autóctona y los inmigrantes en España son relativamente elevados y positivos (Cebolla y González, 2013; Ikuspegi, 2017). Dicho eso, en las narrativas de nuestros participantes se observa algo similar: son escasos los incidentes de discriminación o de conflictos con la población autóctona. De forma general, la convivencia es satisfactoria para las personas inmigrantes latinoamericanas en Euskadi, lo que contribuiría en el proceso general de integración:

«Creo que la relación entre los latinoamericanos y los vascos es muy buena, muchas personas nos tratan como parte de aquí. Son personas que al final te hacen parte, que comprenden que aunque no es tu cultura, pues, intentan incluirte y hacerte parte y que te sientas bien aunque no sea tu país.» (Leined) 
"Algo que me interesó muchísimo fue aprender euskera. Lo he intentado y a pesar de los años no pierdo la ilusión de aprender un poco más [...] Y la verdad que fue algo que me ayudó para integrarme con la gente porque, a pesar de que el vasco tiene una fama de cerrado y de duro, a mí me parece una gente encantadora y la comunicación que tenemos es óptima.» (Andrés)

«Al principio pensaba que podía tener inconvenientes a la hora de comunicarme, de pillar las bromas o como que no nos íbamos a sentir cómodos, como “¿y de qué hablo con estos?” pero no, es igual. Es normal. Nos entendemos muy bien, nos hacemos bromas, nos contamos cosas.» (Miriam)

En resumen, las relaciones entre las personas inmigrantes y las autóctonas son buenas, incluso en un momento de crisis sanitaria y socioeconómica como el actual. Además, son contactos directos, íntimos y satisfactorios según las narrativas escuchadas.

\subsection{El proyecto migratorio}

Según Moreno-Colom y De Alós (2015), y desde la perspectiva de las personas inmigrantes, la creencia de que el proyecto migratorio tiene sentido y valió la pena emprenderlo colaboraría con una mayor percepción y sentimiento de integración sociocultural. Así se deduce de la última Encuesta Nacional de Inmigrantes del INE (2007) que indica que la mayoría de los inmigrantes ha conseguido mejorar sus condiciones concretas en comparación con las que contaban en sus países de origen. Teniendo en cuenta las narrativas de las personas participantes cada uno de ellas manifiesta que su proyecto migratorio valió la pena y que el emigrar les ha conllevado cambios positivos en sus vidas. Sin embargo, también apuntan algunas dificultades, sobre todo la lejanía de los familiares y un posible impacto causado por la pandemia del Covid-19.

«Sí, yo creo que sí, que valió la pena porque al menos mi mamá puede estar más tranquila y yo creo que sí. Y fue en el momento que tenía que ser porque los planes de venir eran desde mucho antes pero no tomaba la decisión. Pero tenía que ser en el tiempo que tenía que ser. Yo creo que sí, que fue bueno.» (Leined)

«Mira, antes de la pandemia sí pero ahora lo veo muy complicado. Para todos, pero más sobre todo para nosotros, los inmigrantes. Esto va a tardar en recuperarse, no sé cómo vayamos a salir, pero en estas situaciones los que peor la pasan son los de abajo, los inmigrantes.» (Vanesa)

«Sin dudas he podido avanzar y mejorar en lo económico.» (Erick)

También vale señalar que las narrativas apuntan que los proyectos migratorios y vitales se orientan a la permanencia y al establecimiento, si no definitivo, de larga duración en Euskadi. 


\subsection{Críticas}

Finalmente, y en línea con la idea de que el concepto de integración no resulta claro ni inequívoco, los participantes han indicado ciertas resistencias, críticas e, incluso, discursos de rechazo ante el término «integración», como se ha observado en otros estudios (Verdía Varela et al., 2020):

"Cuando decimos "integración” significa formar parte integral de otro cuerpo. Eso es integrar, integrarse uno mismo en otros. Y si se pone en eso términos no sé si se pueda hablar de "integración”. Tal vez necesitamos inventar o usar una palabra distinta a la de integración. Adaptarse, convivir, tolerar, no sé.» (Ángela)

«Con el tema de la integración creo que a veces lo han malinterpretado, de parte de autóctonos e inmigrantes. Creo que la palabra no termina de convencernos a todos.» (Vanesa)

«Hablar de integración cuando uno ha nacido aquí o lleva más de dos décadas es un oxímoron, como suele decirse.» (Nicolás)

\section{APUNTES FINALES}

Las narrativas de los/as participantes apuntan a que el proceso de integración debe involucrar tanto a las propias personas inmigrantes como a las instituciones y a la sociedad de acogida. Para alcanzar la integración debe compartirse la responsabilidad y deben «ajustarse» de forma mutua las personas inmigrantes y las autóctonas. Para ello son imprescindibles la comunicación, las interacciones y el diálogo entre inmigrantes y la sociedad, sus instituciones y la población autóctona. Las personas inmigrantes subrayan la idea de reciprocidad tanto en las interacciones como en los derechos y responsabilidades. También se exige actitud de comprensión y de brazos abiertos, expresándose que la interacción entre las personas es un aspecto fundamental del proceso, poniendo énfasis en el respeto mutuo y la interacción intercultural como elementos clave para lograr la integración. En líneas generales, las narrativas apuntan a un enfoque integrativo holístico que requiere un diálogo cultural como elemento fundamental.

Podemos pensar que las personas inmigrantes rechazan el enfoque asimilacionista ya que en las narrativas se ha señalado la convicción de no renunciar a las diferencias culturales en la vida cotidiana. Sin embargo, es una "asimilación condicionada»: las personas participantes afirman que ellas también deben aceptar ciertos valores nucleares de la sociedad de acogida, pero sin que su presencia y el mantenimiento de su idiosincrasia y elementos culturales sean una posible fuente de conflicto para la convivencia. Es decir, se podría pensar que las narrativas de las personas inmigrantes se aproximan a un «asimilacionismo moderado» (Megías Quirós, 2008), que promueve el diálogo, el mantenimiento de sus tradiciones y la adopción y respeto de los valores autóctonos, en línea con lo reco- 
gido en el Plan Estratégico Ciudadanía e Integración que define el concepto de integración como un «proceso bidireccional y dinámico de ajuste mutuo por parte de todos los inmigrantes y residentes de los Estados miembros», con el ineludible "respeto de los valores básicos de la Unión Europea» (2007: 26). De igual modo, la noción de integración se ha asociado, a veces, con prácticas asimilacionistas, por lo que algunas personas han criticado su bagaje ideológico, incierto y vago. Es decir, es un término resistido y posiblemente en disputa, que no convence a todos los inmigrantes.

De todas maneras, hay cierta coincidencia, en el plano teórico, de gran parte de las narrativas, con los discursos oficiales y las definiciones de integración expuestas: se subraya la bidireccionalidad, el ajuste mutuo, la importancia de las interacciones sociales y de la necesidad de poder desarrollar y mantener la cultura propia, que se trata de un proceso multidimensional (cultural, económico, social), que deben respetarse los valores mutuos, entre otras coincidencias.

Por otra parte, desde un marco jurídico se ha señalado que el modelo migratorio español ha estado focalizado en las necesidades del mercado laboral vinculando la situación regular de los inmigrantes a su cotización en la Seguridad Social (Martín Patino, 2011). Esto está en consonancia con la idea de que para aproximarse a cierta idea de integración es necesario un empleo y en nuestras narrativas la importancia de lo laboral a la hora de comenzar a hablar de integración es enfatizado por varios participantes. De forma general, en la Unión Europea las políticas de integración están vinculadas a la estrategia europea de empleo (Larsson, 2015). De este modo, el empleo es el camino privilegiado hacia la inserción en la sociedad, y los conceptos de inclusión y exclusión social se repiten constantemente en la política social y de empleo de la Unión Europea (Brännström et al., 2017).

Se ha señalado que las políticas de integración deben apartarse de posturas asimilacionistas, que hacen hincapié en que los/as nuevos/as integrantes adopten la cultura de la nueva sociedad. Puesto esto, se ha indicado que las acciones en pro de la integración deben respetar la diversidad cultural, pero dando la posibilidad de que las personas inmigrantes adopten pautas culturales autóctonas ya que esto les daría mayor autonomía (Goodman 2010), en consonancia con algunas de nuestras narrativas. Por tanto, según las narrativas presentadas la integración sería un proceso social dinámico, transversal, que requiere tiempo y debe ser renovado; que precisa de la acción activa de las personas inmigrantes y también de la sociedad de acogida, y que hay que adaptarse a los valores básicos de esa sociedad como también contar con la posibilidad de establecer pautas y valores propios (Evanoff, 2006).

De forma general, los participantes señalan la importancia de los tres niveles propuestos por Solé et al. (2002): el estructural, cuando hacen hincapié en la importancia del empleo para comenzar a insertarse en la nueva sociedad; el cultural, vinculado al derecho a experimentar y vivir sus tradiciones y cultura bajo unos parámetros de respeto y conviven- 
cia; y el jurídico, cuando subrayan la necesidad de igualdad de derechos y acceso a los bienes sociales. De igual modo, como apuntan algunos autores la integración debería darse cuando uno se convierte en una parte aceptada de la sociedad (Pennix y Martiniello, 2006) $y$, en ese sentido, algunos participantes han manifestado la importancia del aspecto subjetivo en dicho proceso.

Más allá del acercamiento particular de este articulo creemos que se puede extraer un retrato o perfil general del proceso de integración del colectivo inmigrante latinoamericano en la CAPV. En síntesis, y no obstante a los problemas de concreción y definición teórica, las narrativas de las personas inmigrantes latinoamericanas señalan a la integración como valiosa en sí misma, como un proceso inclusivo y colectivo, bidireccional, asimétrico e interdependiente con la sociedad de destino.

\section{REFERENCIAS BIBLIOGRÁFICAS}

Aierdi Urraza, X. (2018). En pos de un futuro razonable en G. Moreno Márquez (coord.), El proceso de integración del colectivo inmigrante en Euskadi. Análisis de la Encuesta de la Población Inmigrante Extranjera en la CAE (EPIE2014). Bilbao: Universidad del País Vasco, Servicio Editorial, 274 pp.

Ares Mateos, A. y Fernández Garcia, M. M. (2017). El caleidoscopio de la integración. Hacia un modelo mixto desde la perspectiva de los migrantes. Revista de Fomento Social, 72(2), 157-201.

Bouhris, R. Y., Moïse, L. C., Perreault, S. y Senecal, S. (1997). Towards an interactive Acculturation Model: A Social Psychology Approach. International Journal of Psychology, 32(6), pp. 369-386.

Brännström, L., Giritli-Nygren, K., Lidén, G. y Nyhlén, J. (2018). Lived experiences of changing integration policies: Immigrant Narratives of Institutional Support and Labour Market Inclusion/Exclusion in Sweden. NJMR, vol. 8, n. ${ }^{\circ}$ 1, pp. 25-34.

Cachón Rodríguez, L. (2008). La incorporación de y con los inmigrantes en España: debates teóricos, políticas y diversidad territorial. Política y Sociedad, vol. 45, n. ${ }^{\circ}$, pp. 205235.

Cachón Rodríguez, L. (2009). La «España inmigrante»: marco discriminatorio, mercado de trabajo y políticas de inmigración. Barcelona: Anthropos.

Cebolla Boado, H. y González Ferrer, A. (2013). Inmigración ¿integración sin modelo? Madrid: Alianza. 
Conferencia Ministerial Europea sobre Integración (2010). Declaración de Zaragoza. Zaragoza: Presidencia española de la Unión Europea, 15 y 16 de abril de 2010.

Diaz-Serrano, L. (2013). Immigrants, natives and job quality: evidence from Spain. International Journal of Manpower, vol. 34, n. ${ }^{0}$ 7, pp. 753-775.

Ehrkamp, P. (2006). We Turks are no Germans: assimilation discourses and the dialectical construction of identities in Germany. Environment and Planning, vol. 38, pp. 16731692.

Erdal, M. B. y Oeppen, C. (2013). Migrant balancing acts: understanding the interactions between integration and transnationalism. Journal of Ethnic and Migration Studies, vol. 39, n. $^{\circ}$ 6, pp. $867-84$.

Eriksen, T. H. (2011). What is a society? Ethnicities, vol. 1, n. ${ }^{\circ}$ 1, pp. 18-22.

Evanoff, R. J. (2006). Integration in intercultural ethics. International Journal of Intercultural Relations, vol. 30, n. ${ }^{\circ}$, pp. 421-437.

Fernández, C. y C. Ortega (2008). Labor market assimilation of immigrants in Spain: Employment at the expense of bad job-matches? Spanish Economic Review, vol. 10, pp. 83-107.

Gil, S. (2011). Las argucias del concepto de integración. Una exploración por el paisaje europeo. Oñati socio-legal series, vol. 1, n. ${ }^{\circ}$, pp. 1-22.

Gobierno Vasco. Departamento de Igualdad, Justicia y Políticas Sociales (2018). Pacto Social Vasco para la Migración.

Godenau, D., Rinken, S., Martínez, A. y Moreno, G. (2015). La integración de los inmigrantes en España: fases, patrones y dinámicas regionales durante el periodo 2007-2015. Madrid: Documentos del Observatorio Permanente de la Inmigración.

Goodman, S. W. (2010). Integration Requirements for Integration's Sake? Identifying, Categorising and Comparing Civic Integration Policies. Journal of Ethnic and Migration Studies, vol. 36, n. ${ }^{\text {5 }}$, pp. 753-772.

González Rábago, Y. (2013). La migración transnacional y los procesos de Integración en las sociedades de destino. Una mirada a la población colombiana residente en la Comunidad Autónoma del País Vasco. Tesis doctoral, España: Universidad del País Vasco.

Göttsch, M. (2010). Inmigración latinoamericana en España: el estado de la investigación, en A. Ayuso y G. Pinyol (coords.), Inmigración Latinoamericana en España. El estado de la investigación. Barcelona: CIDOB. 
Hamberger, A. (2009). Immigrant Integration: Acculturation and Social Integration. Journal of Identity and Migration Studies, vol. 3, n. ${ }^{\circ}$ 2, pp. 1-21.

Hughes, E. C. y Hughes, H. M. (1952). Where Peoples Meet: Racial and Ethnic Frontiers. Glencoe: Free Press.

II Plan Estratégico de Ciudadanía e Integración 2011-2014. Disponible en https://www. fundacionlengua.com/extra/descargas/des_38/INMIGRACION/II-Plan-EstrategicoCiudadania-e-Integracion.pdf.

Iglesias de Ussel, J. (2010). Las políticas de integración social de los inmigrantes en las Comunidades Autónomas españolas. Desarrollo y evaluación. Bilbao: Fundación BBVA.

Iglesias, J., Rua, A. y Ares, A. (2020). Un arraigo sobre el alambre. La integración social de la población de origen inmigrante en España. Madrid: Fundación Foessa.

Ikuspegi (2017). La diversidad infantil y juvenil en la CAE. Las (mal) llamadas segundas generaciones. Bilbao: Editorial de la Universidad del País Vasco.

Ikuspegi (2018). Población de origen extranjero en la Unión Europea. Disponible en https:// www.ikuspegi.eus/documentos/panoramicas/es/pan70casOK.pdf

Ikuspegi (2020). Índice sintético de inclusión e integración. Disponible en https://www. ikuspegi.eus/documentos/panoramicas/pan78cas.pdf.

Lamphere, L. (2007). Migration, assimilation and the cultural construction of identity: Navajo perspectives. Ethnic and racial studies, 30(6), pp. 1134-1137.

Larsson, J. K. (2015). Integrationen och arbetets marknad: hur jämställdhet, arbete och annat "svenskt» görs av arbetsförmedlare och privata aktörer. Atlas Akademi: Stockholm.

Lasheras Ruiz, R. (2018). Perfil socioeconómico y ocupacional. Impacto de la crisis en G. Moreno Márquez (coord.), El proceso de integración del colectivo inmigrante en Euskadi. Análisis de la Encuesta de la Población Inmigrante Extranjera en la CAE (EPIE2014). Bilbao: Universidad del País Vasco, Servicio Editorial, 274 pp.

Lucas, J. de (2008). Los derechos de participación como elemento de integración de los inmigrantes. Bilbao: Fundación BBVA. 
Martin Rojo, L. (2003). Escuela y diversidad lingüística y cultural. En Martin Rojo, L. (eds.), ¿Asimilar o integrar? Dilemas ante el multilingüismo en las aulas (pp. 13-63). Madrid: Centro de Investigación Documentación Educativa, Ministerio de Educación Cultura y Deporte.

Martínez de Lizarrondo Artola, A. (2009). Los procesos de gestión y evaluación de las políticas de integración de inmigrantes en las Comunidades Autónomas. Gestión y análisis de políticas públicas, 1 (2), pp. 101-120.

Meer, N y Moddod, T. (2012). How does interculturalism contrast with multiculturalism? RESR, 33(2), pp. 175-196. doi: 10.1080/07256868.2011.618266

Moreno-Colom, S. y De Alós, R. (2016). La inmigración en España: ¿Una integración con pies de barro? Política y Sociedad, vol. 5, n. ${ }^{\circ}$ 2, pp. 509-528.

Meer, N y Moddod, T. (2012). How does interculturalism contrast with multiculturalism? Journal of Intercultural Studies, vol. 33, n. ${ }^{\circ}$ 2, pp. 175-196.

Megías Quirós, J. J. (2008) Asimilación e interculturalidad en la política de integración social europea. El trasfondo doctrinal. Entelequia Revista Interdisciplinar, vol. 8, pp. 73-97.

Moreno Márquez, G. (2018). El proceso de integración del colectivo inmigrante tras el impacto de la crisis en Euskadi. Hacia una mirada multifocal en G. Moreno Márquez (coord.), El proceso de integración del colectivo inmigrante en Euskadi. Análisis de la Encuesta de la Población Inmigrante Extranjera en la CAE (EPIE2014). Bilbao: Universidad del País Vasco, Servicio Editorial, 274 pp.

Navas, M., Pumares, P., Sánchez, J., García, C., Rojas, A., Cuadrado, I., Asensio, M. y Fernández, J. (2004). Estrategias y actitudes de aculturación: La perspectiva de los inmigrantes y de los autóctonos en Almería. Almería: Junta de Andalucía y Ediciones Al Sur.

OECD (2009). International Migration Outlook. Paris: OECD, SOPEMI.

Park, R. y Burgess, E. (1921). Introduction to the Science of Sociology. Chicago: University of Chicago Press.

Pennix, R. y Martiniello, M. (2006). Procesos de integración y políticas (locales): estado de la cuestión y algunas enseñanzas. Revista Española De Investigaciones Sociológicas, vol. 116, pp. 123-156.

Portes, A. y Börocz, J. (1989). Contemporary Immigration: Theoretical Perspectives on its Determinants and Modes of Incorporation. International Migration Review, 23, pp. 606-630. 
Pujadas, J. J. (1993). Identidad cultural de los pueblos. Madrid: Eudema.

Pumares Fernández, P. (1998). ¿Qué es la integración? Reflexiones sobre el concepto de integración de los inmigrantes. Barcelona: Icaria Antrazyt.

Retortillo Osuna, A. (2009). Evolución de los modelos psicológicos de aculturación en Norteamérica y en Europa: de la unidimensionalidad a la bidimensionalidad en el tratamiento de la inmigración. Revista de Historia de la Psicología, 30(1), 73-86.

Sales Ten, A. (2007). Los recursos formales para la integración de la inmigración. Cuadernos de Geografía, vol. 81-82, pp. 161-186.

Sanz Abad, J. (2009). Entre cumplir y hacer cosas: estrategias económicas y simbolismo en el uso de las remesas de la migración ecuatoriana en España. Tesis doctoral, Universitat Rovira i Virgili, Tarragona, España.

Sebastiani, L. (2009). Inmigración e Integración de Inmigrantes: Políticas Comunitarias y Proceso de Construcción Identitaria de la UE (tesina). Universidad de Granada, España.

Shershneva, J., Fernández Aragón, I. y Oleaga Páramo, J. A. (2018). Principales características de los grandes colectivos de población de origen extranjero en la CAE en G. Moreno Márquez (coord.), El proceso de integración del colectivo inmigrante en Euskadi. Análisis de la Encuesta de la Población Inmigrante Extranjera en la CAE (EPIE2014). Bilbao: Universidad del País Vasco, Servicio Editorial, 274 pp.

Smith, D. (2005). Institutional ethnography: a sociology for people. Lanham: Rowman \& Littlefield:.

Solé, C. (1981). La integración Sociocultural de los inmigrantes en Cataluña. Madrid: CIS.

Solé, C., Alcalde, R., Pont, K., Lurbe, K., Parrilla, S. (2002): El concepto de integración desde la sociología de las migraciones. Revista Migraciones, vol. 12, pp. 9-41.

Taylor, S. J. y Bogdan, R. (1987). Introducción a los métodos cualitativos de investigación. Barcelona: Paidós Editorial.

Tharmalingam, S. (2011). Homeland Orientation of War-Torn Diasporas: Remittances and Cultural Practices of Tamils and Somalis in Norway. PhD tesis. Oslo: Universidad de Oslo, Departamento de Sociología y Geografía Humana.

Torres, F. (2011). La inserción de los inmigrantes: luces y sombras de un proceso. Madrid: Talasa Ediciones. 
Unión Europea (2020). Plan de Acción sobre Integración e Inclusión 2021-2027. Preguntas y respuestas. Disponible en https://ec.europa.eu/commission/presscorner/detail/es/ qanda_20_2179

Verdía Varela, V., Fernandez Suarez, B. y DePalma, R. (2020). What is Integration? A Comparative View from Immigrants and Municipal Policy. International Migration, vol. 58, n. ${ }^{\circ}$, pp. 128-143.

Vicente Torrado, T. (2006). La inmigración latinoamericana en España. UN/PO/EGMMIG/2005/12, Population Division, United Nations Secretariat, México.

Zapata-Barrero, R. (2002). El turno de los inmigrantes. Esferas de justicia y políticas de acomodación. Madrid: IMSERSO.

Zetter, R. y Flynn, D. (2005). Immigration, Social Cohesion, and Social Capital: What are the Links? Oxford: Oxford Brookes University. 